\title{
Anidación del Gorrión Criollo Zonotrichia capensis (Emberizidae) en Quito, Ecuador
}

\author{
Héctor Cadena-Ortiz \\ Museo Ecuatoriano de Ciencias Naturales, Instituto Nacional de Biodiversidad. Calle Rumipamba 341 y Av. de los Shyris, Casilla: 17-07-8976, Quito, \\ Ecuador; y, Aves Quito (Club de Observadores de Aves de Quito). \\ Correo electrónico:fercho_cada@yahoo.es \\ Editado por/Edited by: Juan Freile \\ Recibido/Received: 25/09/2016. Aceptado/Accepted: 29/03/2017. \\ Publicado en línea/Published online: 08/02/2018.
}

DOI: http://dx.doi.org/10.18272/reo.v0i3.748

\section{Nesting of Rufous-collared Sparrow Zonotrichia capensis (Emberizidae) in Quito, Ecuador}

\begin{abstract}
Resumen
Incrementar información sobre la biología reproductiva siempre es útil para evidenciar patrones. En este trabajo presento los detalles de un nido del Gorrión Criollo Zonotrichia capensis en forma de taza abierta, construido principalmente con fibras vegetales y una cubierta interior de pelos de mamífero, observado entre noviembre 2015 y julio 2016. El nido fue construido en un macetero colgante en una casa de un barrio céntrico de la ciudad de Quito. Dos huevos de color celeste pálido con manchas pardas fueron incubados durante 14 días. Estimé un periodo de 11 días de construcción del nido, 2 días de puesta y 14 de empollamiento.
\end{abstract}

Palabras clave: Chingolo, huevos, incubación, nido, pichones, Quito, reproducción.

\begin{abstract}
Increasing information about the breeding biology of bird species is useful for evidencing patterns. In this study, I present observations of an open cup nest of Rufous-collared Sparrow Zonotrichia capensis, built primarily with plant fibers and an inner lining mammalian hair, which was observed from November 2015 through July 2016. The nest was built in a pendant flowerpot at a house located in the downtown of Quito. Two pale bluish eggs speckled with brown were incubated. I estimated a period of 11 days for nest building, 2 days for egg laying, 14 days for incubation, and 14 days for brooding.
\end{abstract}

Keywords: breeding, eggs, incubation, nest, nestlings, Quito, Rufous-collared Sparrow.

\section{INTRODUCCIÓN}

El Gorrión Criollo o Chingolo Zonotrichia capensis es una de las aves más comunes en los Andes ecuatorianos, con un rango altitudinal de 1500 a $3500 \mathrm{~m}$ (Ridgely \& Greenfield, 2001). Globalmente se distribuye desde el sur de México hasta la Patagonia (Rising et al., 2011). Se cree que se reproduce durante todo el año (Miller, 1959; Class et al., 2011; Rising et al., 2011), pero la información sobre sus periodos de incubación o anidamiento aún es limitada (Rising et al., 2011). Eikenaar et al. (2013) mencionan que todavía se desconoce las causas de las diferencias en la fenología de cría entre poblaciones de Z. capensis. Por ejemplo, en Papallacta, provincia de Napo, se evidenció un pico marcado de reproducción entre septiembre y diciembre (Moore et al., 2005), pero en Las Caucheras, provincia de Napo, no se evidenció ningún pico reproductivo a lo largo del año (Class et al., 2011). En ambos trabajos se resalta a la elevación y al clima, como principales factores influyentes en la fenología reproductiva. 
Ortiz-Crespo \& Carrión (1991) mencionan que Zonotrichia capensis tiene un sistema social monogámico y territorial, una puesta de 2-3 huevos que son incubados en menos de dos semanas y un periodo similar para el desarrollo de los polluelos, que son atendidos por ambos adultos. En Ecuador, hay registros de un nido con tres huevos en diciembre 1996, en vegetación baja en un pastizal en San Isidro, provincia de Napo, a $1700 \mathrm{~m}$ (Greeney, 1999); un volantón en diciembre 2003, cerca de la reserva Tapichalaca, provincia de ZamoraChinchipe, a $2500 \mathrm{~m}$ (Greeney et al., 2010); adultos acarreando material para construcción de nido en junio 2004; pichones en enero 2007; y adultos construyendo un nido en diciembre 2009, en Quito, provincia de Pichincha (Greeney et al., 2011). En el presente trabajo reporto el seguimiento de un nido de Z. capensis observado desde el 6 de noviembre de 2015 hasta el 9 de julio de 2016, en una casa del barrio La Tola, Quito, provincia de Pichincha $\left(0,138^{\circ} \mathrm{S} ; 78,301^{\circ} \mathrm{O}\right)$. Registré el nido esporádicamente mediante observaciones, fotografías (Fig. 1) y videos. No tomé medidas ni pesos de los huevos o pichones para prevenir el posible abandono del nido.

El nido consistió en una taza abierta, construida sobre una maceta que contenía una planta viva de Geranio Pelargonium sp. (Geraniaceae). La maceta tenía un diámetro de $23 \mathrm{~cm}$, colgaba a $190 \mathrm{~cm}$ del suelo y se encontraba $40 \mathrm{~cm}$ por debajo de una cornisa de $38 \mathrm{~cm}$ de ancho. Dejé el nido intacto en espera de reutilización del mismo, pero el 9 de julio de 2016 el nido fue encontrado en el suelo. El nido midió $13 \mathrm{~cm}$ de diámetro externo; $4,5 \mathrm{~cm}$ de altura externa; $5 \mathrm{~cm}$ de diámetro interno; y 2,3 $\mathrm{cm}$ de profundidad interna. $\mathrm{Su}$ peso al 9 de julio de 2016 fue de 25,4 g, luego de haberse secado naturalmente. La estructura del nido podía dividirse en dos secciones: una cobertura interna formada por pelos de mamífero $(2,3 \mathrm{~g})$ y la parte externa compuesta principalmente por fibras vegetales entretejidas con pelos de mamíferos $(18,9 \mathrm{~g})$, fibras textiles o hilos $(1,3 \mathrm{~g})$, fibras plásticas azules $(0,4 \mathrm{~g})$, tres plumas $(>0,1 \mathrm{~g})$ y una banda negra de caucho de 0,1 $\mathrm{cm}$ de ancho y $70 \mathrm{~cm}$ de circunferencia $(1,9 \mathrm{~g})$.

Realicé cuatro videos del nido, de una hora cada uno, a partir de las 7 h00 en diferentes días. El 4 de noviembre, un adulto dejó pajas en el nido por cuatro ocasiones; en dos ocasiones llevó pajas y las acomodó primero con su pico y luego se sentó en el nido y realizó movimientos con todo su cuerpo, posiblemente para compactar el material. El 7 de noviembre, un adulto llevó material vegetal al nido por cinco ocasiones, lo arregló también sentándose y moviendo su cuerpo sobre el nido. Estos eventos tomaron 27-35 s. El 30 de noviembre, un adulto llegó al nido con comida por cuatro ocasiones, la entregó a los pichones y se fue. En otras tres ocasiones, un adulto llegó con comida al nido, entregó a los pichones, se tragó los sacos fecales y cubrió a los pichones para empollarlos. Estas visitas tomaron 1 min 30 s, 5 min 12 s y 5 min, cada una. En otra ocasión, un adulto se sentó a empollar a los pichones, llegó un segundo adulto que entregó comida al adulto que empollaba, y luego ambos adultos alimentaron a los pichones. Finalmente, el 02 de diciembre, un adulto regurgitó comida por cinco ocasiones a los pichones y se fue. Estos eventos de alimentación duraron 12-17 s. En uno de estos eventos, el adulto se llevó un saco fecal. En otras tres ocasiones, un adulto trajo comida a los pichones y luego los empolló durante $35 \mathrm{~s}, 10$ min y 2 min $13 \mathrm{~s}$. En una de estas visitas, el adulto se comió un saco fecal. En otras dos ocasiones, mientras un adulto empollaba llegó un segundo adulto, le entregó comida al que empollaba, y luego ambos alimentaron a los pichones. En cinco ocasiones los adultos trajeron abejas (Apis mellifera) como alimento a los pichones. He observado frecuentemente, a lo largo de cinco años, a individuos de Zonotrichia capensis consumir A. mellifera muertas, seleccionándolas bajo una colmena artificial que hay en un balcón de la casa del nido estudiado.

Estimé un periodo de construcción del nido de 11 días, considerando que la pareja de Zonotrichia capensis colocó fibras vegetales en la maceta desde el 3 de noviembre hasta el 13 de noviembre, un día antes de la puesta del primer huevo. El periodo de puesta pudo ser de dos días, considerando que Miller \& Miller (1968) mencionan que la puesta usual de Z. capensis es de dos huevos en dos días consecutivos. El primer huevo fue desovado el 14 de noviembre, el 15 y 16 de noviembre no realicé visitas al nido y el 17 de noviembre ya estaban los dos huevos. Estimé 14 días de periodo de incubación, desde la puesta del último huevo (15 de noviembre) hasta un día previo a la eclosión de los dos huevos; el 29 de noviembre se observó ya dos pichones en el nido. Estimé 14 días de empollamiento hasta que ambos pichones abandonaron el nido el 12 de diciembre. Sólo evidencié la participación de ambos padres en la alimentación de los pichones, pero no pude distinguir roles entre sexos debido a que Z. capensis no presenta dimorfismo sexual en plumaje (Greeney et al., 2010). Sin embargo, Miller \& Miller (1968) identificaron mediante laparoscopia que solo la hembra construye el nido e incuba. 

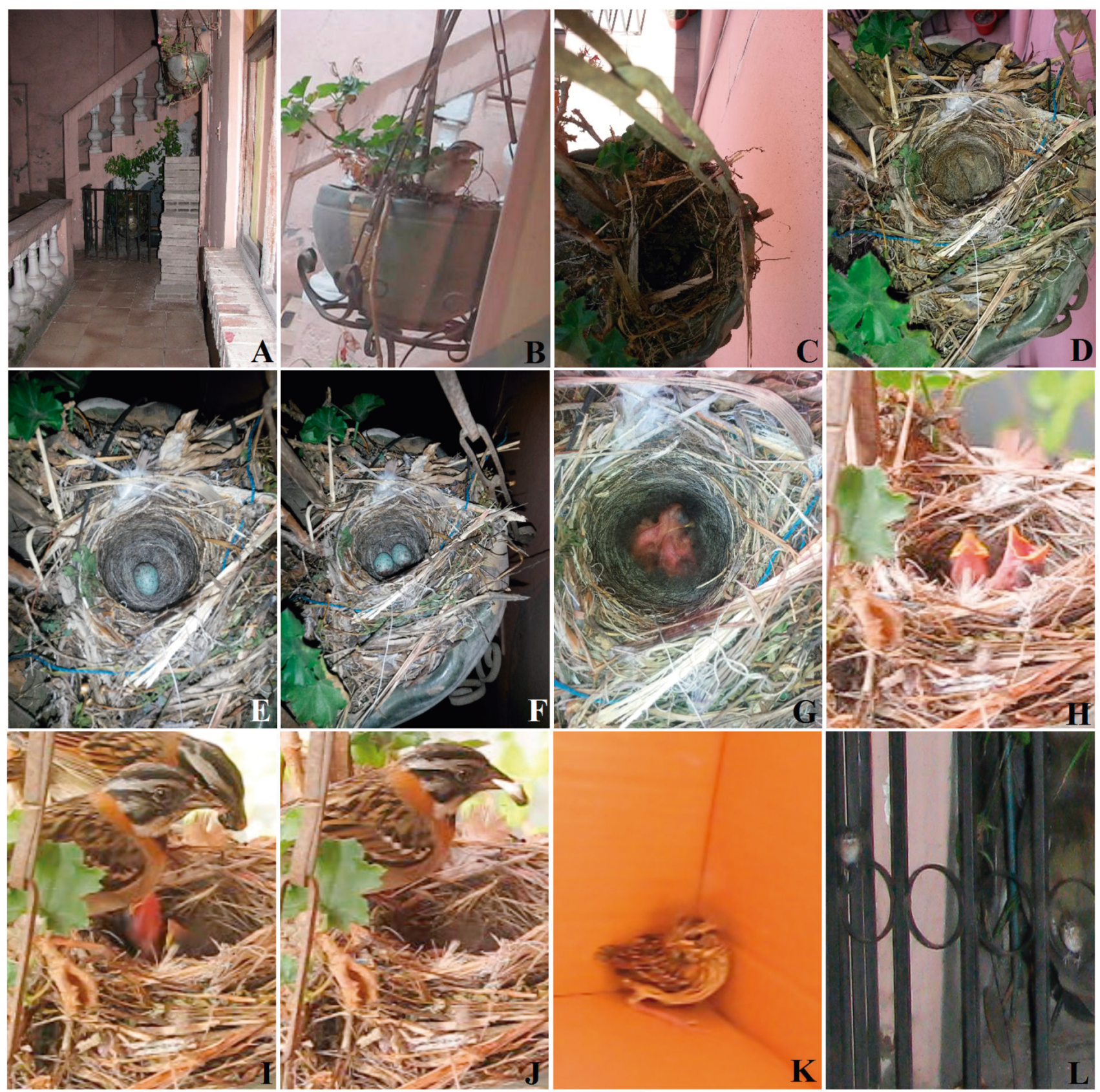

Figura 1: Seguimiento de la anidación del Gorrión Criollo Zonotrichia capensis en Quito: A) ubicación de la maceta donde se construyó el nido; B) adulto acarreando material al nido; C) nido al tercer día de construcción, 8 de noviembre de 2015; D) nido al sexto día de construcción, 11 de noviembre, ya con cubierta de pelos al interior de la copa; E) nido con el primer huevo, 14 de noviembre; F) nido con dos huevos, 17 de noviembre; G) pichones probablemente al primer día de nacidos, 29 de noviembre; H) pichones de cuatro días de nacidos pidiendo comida, 02 de diciembre; I) adultos entregando comida, el de la izquierda entrega una Apis mellifera, 02 de diciembre; J) adulto con saco fecal en su pico, 02 de diciembre; K) volantón de 14 días de edad, recién salido del nido, 12 de diciembre; L) volantones de 16 días de edad, perchados en la cercanía del nido, 14 de diciembre. 
El 13 y 14 de diciembre, los volantones perchaban a baja altura en las cercanías del nido, dentro de la casa. El 18 de diciembre observé dos adultos y dos pichones perchados en los alambres eléctricos fuera de la casa. Era muy probable que se tratara de los mismos individuos monitoreados. De acuerdo a Miller (1959), los juveniles van perdiendo progresivamente el estriado ventral de su plumaje. No volví a observar con certeza a estos individuos, por lo que no pude establecer un periodo de dependencia. Fraga (1978) observó a volantones permanecer en el territorio parental por al menos 19 días.

La dieta de Zonotrichia capensis incluye semillas, insectos, lombrices, pedazos de frutas, follaje y migas de pan, entre otros desperdicios caseros (Ortiz-Crespo \& Carrión, 1991). En un barandal frente al nido frecuentemente colocaba migas de pan o restos de arroz, los que eran consumidos rápidamente por varios individuos de Z. capensis. Durante el periodo de reproducción de la pareja observada, estos consumieron muy poco los restos dejados. Se podría conjeturar que en durante este periodo tienen preferencia por fuentes de proteína como insectos en lugar de carbohidratos. Se ha establecido previamente que los pichones y volantones de esta especie son alimentados con insectos (Miller \& Miller, 1968; Wolf, 1969).

Las poblaciones urbanas de Zonotrichia capensis están siendo afectadas por el estrés de la fragmentación de hábitats en ambientes urbanos (Ruiz et al., 2002), conflictos con el Gorrión Europeo Passer domesticus, especie introducida (Ortiz-Crespo, 1977) y parasitación de sus nidos por parte del Vaquero Brilloso Molothrus bonariensis, del cual Z. capensis es uno de sus principales hospederos (Fraga, 1978). En Quito se ha reportado recientemente la parasitación de M. bonariensis a Z. capensis (Crespo-Pérez et al., 2016). Otro factor también puede ser la depredación de huevos y pichones por roedores o felinos, por la vulnerabilidad de sus nidos construidos principalmente sobre o cerca del suelo (Fraga, 1978).

\section{AGRADECIMIENTOS}

Agradezco a Daniela Bahamonde por su continuo estímulo para escribir y por estar pendiente de estos pichones y de las nuestras; agradezco también a los padres de Dani por la misma labor. También a Eli Montenegro por la ayuda con las fotos.

\section{REFERENCIAS}

Class, A. M., Wada, H., Lynn, S. E., \& Moore, I. T. (2011). The timing of life-history stages across latitudes in Zonotrichia sparrows. Condor, 113(2), 438-448. doi: http://dx.doi.org/10.1525/cond.2011.100068

Crespo-Pérez, V., Pinto, C. M., Carrión, J. M., Jarrín-E, R. D., Poveda, C., \& de Vries, T. (2016). The Shiny Cowbird, Molothrus bonariensis (Gmelin, 1789) (Aves: Icteridae), at 2,800 m asl in Quito, Ecuador. Biodiversity Data Journal, 4, e8184. doi: http://dx.doi.org/10.3897/BDJ.4.e8184

Eikenaar, C., Bonier, F., Martin, P. R., \& Moore, I. T. (2013). High rates of extra-pair paternity in two equatorial populations of Rufous-collared Sparrow, Zonotrichia capensis. Journal of Avian Biology, 44(6), 600-602. doi: http://dx.doi.org/10.1111/j.1600-048X.2013.00212.x

Fraga, R. M. (1978). The Rufous-collared Sparrow as a host of the Shiny Cowbird. Wilson Bulletin, 90(2), $271-284$. Recuperado de: http://www.jstor.org/stable/4161057

Greeney, H. F. (1999). Ecuadorian birds: some nesting records and egg descriptions. Avicultural Magazine 105, 127129.

Greeney, H. F., Juiña, M. E., Harris, J. B. C., Wickens, M. T., Winger, B., Gelis, R. A., Miller, E. T., \& Solano-Ugalde, A. (2010). Observations on the breeding biology of birds in south-east Ecuador. Bulletin of the British Ornithologists Club, 130(1), 61-68. Recuperado de: http://www.biodiversitylibrary.org/page/47499620\#page/65/mode/1up 
Greeney, H. F., Martin, P. R., Gelis, R. A., Solano-Ugalde, A., Bonier, F., Freeman, B., \& Miller, E. T. (2011). Notes on the breeding of high-Andean birds in northern Ecuador. Bulletin of the British Ornithologists' Club, 131(1), 24-31. Recuperado de: http://www.biodiversitylibrary.org/item/206985\#page/3/mode/1up

Miller, A. H. (1959). Reproductive cycles in an equatorial sparrow. Proceedings of the National Academy of Sciences of the United States of America, 45(7) 1095-1100. doi: http://dx.doi.org/10.1073/pnas.45.7.1095

Miller, A. H., \& Miller, V. D. (1968). The behavioral ecology and breeding biology of the Andean sparrow, Zonotrichia capensis. Caldasia, 10(47), 83-154. Recuperado de: http://www.jstor.org/stable/23641155

Moore, I. T., Bonier, F., \& Wingfield, J. C. (2005). Reproductive asynchrony and population divergence between two tropical bird populations. Behavioral Ecology, 16(4), 755-762. doi: http://dx.doi.org/10.1093/beheco/ari049

Ortiz-Crespo, F. (1977). La presencia del Gorrión Europeo Passer domesticus L., en el Ecuador. Revista de la Universidad Católica, 5(16), 193-197. Recuperado de: http://www.puce.edu.ec/publicaciones/Centro de Publicaciones/ Revistas/Publicaciones/Revista\%2016.pdf

Ortiz-Crespo, F. I. \& Carrión, J. M. (1991). Introducción a las aves del Ecuador. Quito: FECODES.

Ridgely, R. S. \& Greenfield, P. J. (2001). The Birds of Ecuador. Ithaca: Cornell University Press.

Rising, J., Jaramillo, A., Copete, J. L., Madge, S. \& Ryan, P. (2011) Rufous-collared Sparrow Zonotrichia capensis. En: J., del Hoyo, A., Elliott \& D. A. Christie (Eds.) Handbook of the birds of the world. vol. 16. (pp. 545). Barcelona: Lynx Edicions.

Ruiz, G., Rosenmann, M., Novoa, F. F., \& Sabat, P. (2002). Hematological parameters and stress index in Rufous-Collared Sparrows dwelling in urban environments. Condor, 104(1), 162-166. doi: http:// 5422(2002)104\%5B0162:HPASII\%5D2.0.CO;2

Wolf, L. L. (1969). Breeding and molting periods in a Costa Rican population of the Andean Sparrow. Condor, 71(2), 212-219. doi: http://dx.doi.org/10.2307/1366080 